\title{
Equator-to-pole temperature differences and the extra-tropical storm track responses of the CMIP5 climate models
}

Article

Accepted Version

Harvey, B., Shaffrey, L. and Woollings, T. (2014) Equator-topole temperature differences and the extra-tropical storm track responses of the CMIP5 climate models. Climate Dynamics, 43 (5-6). pp. 1171-1182. ISSN 0930-7575 doi:

https://doi.org/10.1007/s00382-013-1883-9 Available at https://centaur.reading.ac.uk/34068/

It is advisable to refer to the publisher's version if you intend to cite from the work. See Guidance on citing.

Published version at: http://link.springer.com/article/10.1007/s00382-013-1883-9

To link to this article DOI: http://dx.doi.org/10.1007/s00382-013-1883-9

Publisher: Springer Berlin Heidelberg

All outputs in CentAUR are protected by Intellectual Property Rights law, including copyright law. Copyright and IPR is retained by the creators or other copyright holders. Terms and conditions for use of this material are defined in the End User Agreement.

www.reading.ac.uk/centaur 
Central Archive at the University of Reading

Reading's research outputs online 


\title{
Equator-to-pole temperature differences and the extra-tropical storm track responses of the CMIP5 climate models
}

\author{
B. J. Harvey ${ }^{1} \quad$ L. C. Shaffrey \\ T. J. Woollings \\ ${ }^{1}$ NCAS-Climate, Department of Meteorology, University of Reading, UK
}

\begin{abstract}
This paper aims to understand the physical processes causing the large spread in the storm track projections of the CMIP5 climate models. In particular, the relationship between the climate change responses of the storm tracks, as measured by the 2-6 day mean sea level pressure variance, and the equator-to-pole temperature differences at upperand lower-tropospheric levels is investigated.

In the southern hemisphere the responses of the upper- and lower-tropospheric temperature differences are correlated across the models and as a result they share similar associations with the storm track responses. There are large regions in which the storm track responses are correlated with the temperature difference responses, and a simple linear regression model based on the temperature differences at either level captures the spatial pattern of the mean storm track response as well explaining between $30-60 \%$ of the inter-model variance of the storm track responses. In the northern hemisphere the responses of the two temperature differences are not significantly correlated and their associations with the storm track responses are more complicated. In summer, the responses of the lower-tropospheric temperature differences dominate the inter-model spread of the storm track responses. In winter, the responses of the upper- and lower-temperature differences both play a role. The results suggest that there is potential to reduce the spread
\end{abstract}


in storm track responses by constraining the relative magnitudes of the warming in the tropical and polar regions.

\section{Introduction}

The extratropical storm tracks are an important component of the climate system. They impact the general circulation of the atmosphere and oceans through the transport of heat, momentum and moisture and they have considerable societal impacts through their associated weather phenomena (Pinto et al. (2007), Dailey et al. (2009), Schwierz et al. (2010)). Being able to predict changes that may occur to the storm tracks is therefore crucially important, both in terms of assessing the potential societal impacts of a modified climate and for understanding other large-scale changes in the atmosphere-ocean system.

The climate change response of the storm tracks has been the focus of a large number of studies in recent years and there is now an emerging consensus as to the qualitative nature of some of the larger-scale changes (e.g. Yin (2005), Bengtsson \& Hodges (2006), Ulbrich et al. (2008), Ulbrich et al. (2009), Catto et al. (2011), Chang et al. (2013) and Zappa et al. (2013)). However, there are still substantial differences in the predictions of current state-of-the-art climate models as to how the storm tracks will respond to climate change (Harvey et al. 2012). In order to increase confidence in climate change projections there is a need to better understand the physical mechanisms causing changes in the storm tracks, and the reasons that projections differ between models.

Numerous mechanisms have been discussed in the literature by which the storm tracks could respond to an altered climate (e.g. Lunkeit et al. (1998), Geng \& Sugi (2003), Lim \& Simmonds (2009), Butler et al. (2010)). Individual storms extract energy from horizontal temperature gradients, therefore any changes to temperature gradients may be expected to affect the storm tracks. In addition to this, the local baroclinicity (as measured for instance by 
the Eady growth rate) is a function of the static stability, with increased stability inhibiting storm growth, so the static stability may also be expected to influence the storm track response to climate change. Finally, the release of latent energy through the condensation of water vapour affects the structure of individual storms and therefore a change in local moisture content may be expected to influence the storm tracks. Changes in the atmospheric moisture content will also have an indirect effect via changes in the large-scale thermal structure of the atmosphere associated with altered latent heat fluxes; however, this effect would be captured by the temperature gradient and stability mechanisms (Schneider et al. 2010).

The zonal-mean warming pattern projected by climate models for the coming century varies with latitude and with height. There are regions of relatively strong warming over the tropics in the upper troposphere and over the polar regions in the lower- to mid-troposphere (see Figure 1 in this paper or Figure 10.7 from Solomon et al. (2007)). As discussed by numerous authors (e.g. Lim \& Simmonds (2009), Butler et al. (2010), Hernández-Deckers \& von Storch (2010)), each region of warming may impact the storm tracks via both the horizontal temperature gradients or the stability mechanisms. The equator-to-pole temperature difference is increased at upper levels by the tropical warming and decreased at low levels by the polar warming. The (dry) static stability, however, is increased in the tropics and subtropics by the tropical warming and decreased in the polar regions by the polar warming. The spatial pattern of the storm track responses can therefore be expected to vary spatially and be dependent on the relative magnitudes of the warming in the tropical upper-troposphere and the polar lower-troposphere.

Several idealised modelling studies have aimed at understanding the impact that each of the regions of enhanced warming have on the extratropical storm tracks in turn, and the mechanisms involved (Lim \& Simmonds (2009), Hernández-Deckers \& von Storch (2010), Butler et al. (2010)). Rind (2008) shows that the relative magnitude of the warming at 
low and high latitudes varies widely between models in the CMIP3 ensemble, therefore it is possible that the differences in the responses of the extratropical storm tracks may be related to differences in the responses of the temperature structure of the atmosphere. The idealised modelling studies give some insight into this and in addition suggest how constraining the temeprature responses in the low and high latitudes may reduce uncertainty in the storm track projections.

This study compliments the idealised modelling experiments by analyzing how the storm track responses in the CMIP5 multi-model ensemble of climate models vary with the responses of the tropospheric temperatures. The inter-model spread in the storm track responses is analysed in terms of the responses of the equator-to-pole temperature differences in the uppertroposphere and in the lower-troposphere. This approach, based on temperature differences rather than the absolute temperature value in each region of warming, captures the intermodel spread associated with the tropical and polar regions of warming whilst recognizing that the equator-to-pole temperature difference is the primary energy source of the extratropical storm tracks. Whilst allowing insight into the sources of spread between the models, this method also highlights the possible drivers of the mean storm track responses.

The paper is organised as follows. The methods and data used are documented in Section 2. Regressions of the storm track responses against the responses of zonal-mean temperature differences are presented in Section 3 and regressions of the storm track responses against the responses of basin-wide equator-to-pole temperature differences are presented in Section 4. A summary and discussion are in section 5 . 


\section{Methodology}

\subsection{Description of models and scenarios}

The data used here is taken from CMIP5 (the fifth phase of the World Climate Research Programme's Coupled Model Intercomparison Project, see Taylor et al. (2012)). Data from the following 24 models is considered in this study: BCC-CSM1.1, BCC-CSM1.1M, CanESM2, CCSM4, CMCC-CM, CNRM-CM5, CSIRO-Mk3.6.0, EC-EARTH, FGOALS-s2, GFDL-ESM2G, GFDL-ESM2M, HadGEM2-CC, HadGEM2-ES, INM-CM4, IPSL-CM5A-LR, IPSL-CM5AMR, IPSL-CM5B-LR, MIROC-ESM, MIROC-ESM-CHEM, MIROC5, MPI-ESM-LR, MPIESM-LR, MRI-CGCM3, NorESM1-M. One ensemble member is used from each scenario for each model, usually the run denoted r1i1p1. The only exceptions, due to data availability, are CCSM4 where r6i1p1 is used and EC-EARTH where r9i1p1 is used. The choice of one ensemble member per model was adopted to avoid the issue of how to weight models which have different numbers of ensemble members. However, an adaption of the 2-way ANOVA framework suggested by Sansom et al. (2013) could be one possible solution.

In this study the responses of the models to future emissions scenarios are considered. In particular, the changes in the model climates between the end of the 20th century (June 1976 - August 2005), using the historical all-forcings experiment (HIST), and the end of the 21st century (June 2070 - August 2099), using both the RCP4.5 and RCP8.5 CMIP5 emissions scenarios (Moss et al. 2010). The figures in this paper show results from the RCP8.5 runs; results are also shown for reference in the Supplementary Material from the same period of the RCP4.5 runs and the main differences between the two scenarios are noted in the text.

\subsection{Model diagnostics and methods}

The measure of storm activity used in this study is the standard deviation of the 2-6 day bandpass-filtered daily-mean mean sea level pressure (MSLP) field, and this will be referred 
to as the storm track in the following. This commonly-used diagnostic provides a simple assessment of synoptic-scale activity using only daily-mean MSLP data (e.g. Hoskins \& Hodges (2002), Chang (2009)). The Lanczos filter with a 61-day convolution vector is used to filter the data, that length having a fairly clean frequency cut-off (Duchon 1979). The filter is applied to the full time-series and then the storm track for each season is calculated by first interpolating the filtered data onto a common n32 Gaussian grid and then taking the standard deviation of each season throughout the relevant time period. The result is a single storm track map for each season of each model run. The responses of the storm tracks are defined for each model as the difference between the seasonal storm track values of the RCP and the HIST runs. In this paper only the winter and summer seasons of each hemisphere are considered.

The equator-to-pole temperature differences are measured using the following two diagnostics. Lower- and upper-level equator-to-pole temperature differences are defined as the difference between the area-average time-mean temperature of the tropical (30S to $30 \mathrm{~N})$ and the polar (north of $60 \mathrm{~N}$ for the $\mathrm{NH}$ and south of $60 \mathrm{~S}$ for the $\mathrm{SH}$ ) regions calculated at the $850 \mathrm{hPa}$ and $250 \mathrm{hPa}$ levels respectively (see Figure 1). These are denoted as $\Delta T 850$ and $\Delta T 250$ and are calculated separately for each hemisphere. Where appropriate, a subscript denotes the hemisphere so that, for instance,

$$
\Delta T 850_{\mathrm{NH}}=T 850_{(30 \mathrm{~S}-30 \mathrm{~N})}-T 850_{(60 \mathrm{~N}-90 \mathrm{~N})}
$$

is the difference between the tropical and northern polar temperatures at the $850 \mathrm{hPa}$ level. In Section 4, longitudinally-confined temperature differences are also defined for the Atlantic and Pacific sectors, and these will be denoted as $\Delta T 850_{\mathrm{ATL}}, \Delta T 250_{\mathrm{ATL}}, \Delta T 850_{\mathrm{PAC}}$ and $\Delta T 250_{\mathrm{PAC}}$ respectively. Note that all of the temperature differences are defined as the tropical temperature value minus the polar temperature value and therefore they are all positive.

In the following, the inter-model spread of the storm track responses is regressed against 


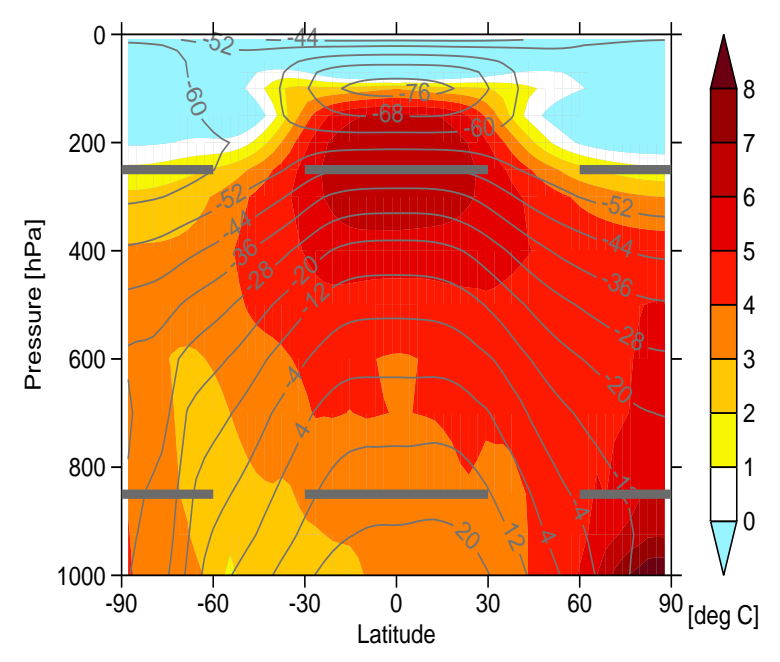

Figure 1: Multi-model, zonal and annual mean HIST temperature (gray contours; units: deg C) and its RCP8.5 response (shading). The horizontal lines indicate the tropical and polar regions used to define the equator-to-pole temperature differences in Section 2.2.

the inter-model spread of the temperature difference responses using simple linear regressions. That is, the numbers $\alpha$ and $\beta$ are calculated at each grid point so as to minimise the RMS of the residuals $\epsilon_{i}$ in the equation

$$
S T_{\mathrm{resp}, i}=\alpha+\beta \Delta T_{\mathrm{resp}, i}+\epsilon_{i}
$$

where $S T_{\mathrm{resp}, i}$ is the storm track response from model $i$ and $\Delta T_{\mathrm{resp}, i}$ is the response of one of the temperature differences from model $i$. The association between the responses of the temperature variables and the storm track variables is assessed by considering maps of the following: the regression slopes $\beta$, the significance of the inter-model correlations between $S T_{\text {resp }}$ and $\Delta T_{\text {resp }}$, and the fraction of variance explained (FVE) by the regression model (2), which is defined as

$$
F V E=1-\frac{\sum \epsilon_{i}^{2}}{\sum S T_{\mathrm{resp}, i}^{2}}
$$

The significance of the inter-model correlations between $S T_{\text {resp }}$ and $\Delta T_{\text {resp }}$ is assessed using 
the t-statistic $t=r / s_{r}$ where $s_{r}=\sqrt{\left(1-r^{2}\right) /(n-2)}$ is the standard error of the inter-model correlation coefficient, $r$, and $n$ is the number of models.

The regression model (2) is designed to capture the inter-model spread of the storm track responses at each grid point. Regions where $\beta$ is positive indicate a positive association between the temperature difference responses and the storm track responses. In some cases it may also be appropriate to consider the influence on the multi-model mean storm track response of the multi-model mean temperature difference response, as predicted by the linear regression model. That is, $\beta$ multiplied by the multi-model mean temperature difference response, and this is discussed in the text throughout this paper.

\section{Hemispheric Results}

\subsection{Storm track responses}

Figure 2 shows the multi-model mean storm track from the HIST experiment (contours) and the RCP8.5 climate change responses for the winter and summer seasons of each hemisphere. The patterns of the responses are qualitatively similar to those produced in other CMIP5 studies using similar diagnostics, for instance Chang et al. (2013) and Harvey et al. (2012). The $\mathrm{NH}$ exhibits a general weakening of the storm tracks during winter, with localised increases over the ocean basins and western Europe. During summer, the NH decrease is apparent over most of the mid-latitude region, with increases largely confined to the Arctic basin. During summer in the SH, the response is a poleward shift of the storm track maximum and a weakening across the subtropics. In contrast, the storm track magnitude increases almost everywhere in the $\mathrm{SH}$ winter, with little sign of a poleward shift, and decreases are confined to the subtropical Pacific region. In this study we restrict attention to the CMIP5 simulations, however we note briefly that Harvey et al. (2012) compare the wintertime responses of the storm tracks in CMIP3 and CMIP5 and show that the responses in the two ensembles are vey 
(a) winter multi-model mean

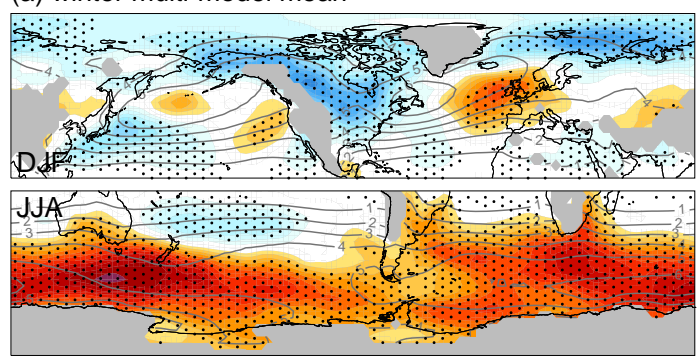

(c) summer multi-model mean

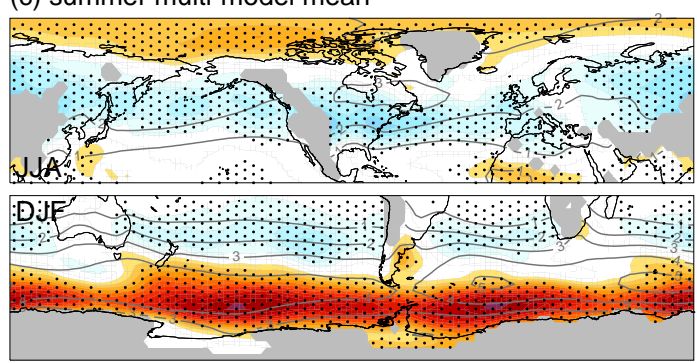

(b) winter inter-model std dev

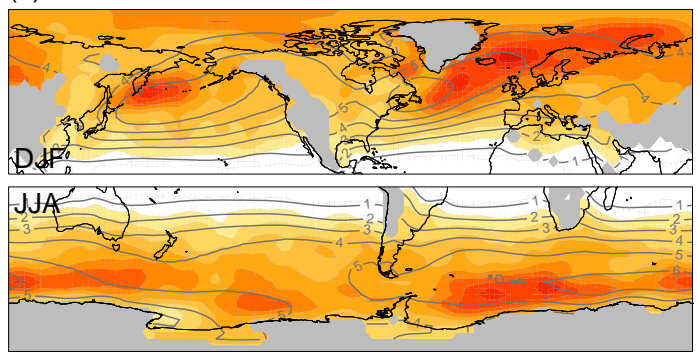

(d) summer inter-model std dev

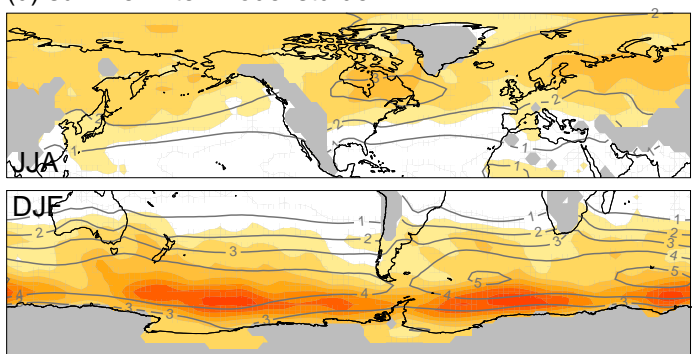

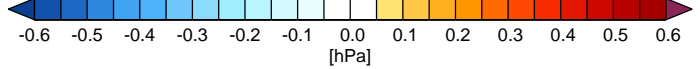

Figure 2: Multi-model mean HIST storm tracks (contours; units: hPa) with (a and c) the multi-model mean storm track response under RCP8.5 (shading), and (b and $\mathbf{d}$ ) the intermodel standard deviation of the responses under RCP8.5 (shading). In panels (a and c) stippling indicates that the multi-model mean response is non-zero at the $95 \%$ confidence level according to a Student's t-test. In this and future plots, the seasons used are indicated in each sub-panel; panels $\mathbf{a}$ and $\mathbf{b}$ show the winter for each hemisphere and panels $\mathbf{c}$ and $\mathbf{d}$ show the summer for each hemisphere. 


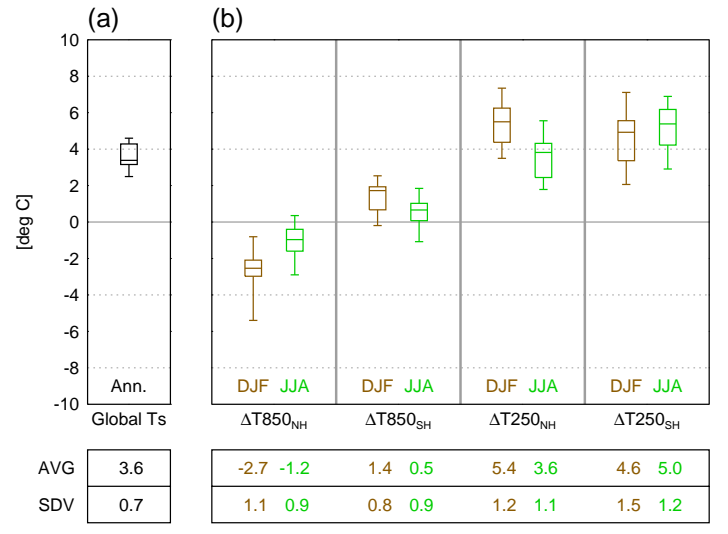

Figure 3: Box-and-whisker symbols illustrating the median, inter-quartile range and the full range of the individual model responses of the (left column) annual-mean global surface temperature and (other columns) the zonal-mean DJF and JJA equator-to-pole temperature differences (as defined in Section 2.2); the lower section displays the multi-model mean (AVG) and inter-model standard deviation (SDV) of each difference.

similar, with the main differences confined to the NH sub-polar regions.

Also shown in Figure 2 is the inter-model standard deviation of the storm track responses for each season. The inter-model standard deviation is large in the SH where the mean responses are largest. It is also large in the $\mathrm{NH}$ storm tracks during winter, where the mean responses are weaker. The aim of the current work is to understand which physical processes are causing the large spread between the models, and in particular what role the changes in the equator-to-pole temperature differences play in determining the storm track responses.

\subsection{Temperature difference responses}

The equator-to-pole temperature differences used here are defined in Section 2.2 and consist of seasonal-mean values of the equator-to-pole temperature difference at a lower-tropospheric level $(850 \mathrm{hPa})$ and at an upper-tropospheric level $(250 \mathrm{hPa})$. Figure 3 shows the range of 
model responses of each temperature difference for both summer and winter. Also shown for reference is the range of responses of the global mean surface temperature $(T \mathrm{~s})$. As noted by Rind (2008) for the CMIP3 models, the spread in the temperature difference responses is larger than the spread of the global mean surface temperature responses.

The upper-level temperature difference increases in all models in both hemispheres and in both of the seasons considered. That is, the upper-tropospheric tropical region consistently warms more than the upper-tropospheric polar regions. The lower-level temperature difference increases in the multi-model mean in the $\mathrm{SH}$ and decreases in the NH. Therefore there is an asymmetry between the responses of the low-level temperature differences in the $\mathrm{NH}$ and $\mathrm{SH}$, as can be seen in the cross section of Figure 1. However, the only lower-level temperature difference with a complete agreement on the sign of responses between the models is $\Delta T 850_{\mathrm{NH}}$ in DJF.

It is informative to consider the relative role of the temperature responses in the tropical and polar regions in determining the model spread in the responses of the temperature differences. Table 1 shows the values of the inter-model correlations between each temperature difference response and the surface temperature response averaged over the tropical region and over the relevant polar region. The spread in the responses of the upper-level temperature differences is dominated by the contribution from the tropical region, with particularly high correlation values for the SH temperature difference response. In contrast, the spread in the responses of the low-level temperature differences is dominated by the polar temperature response, with the exception of the SH summer difference response for which both the tropical and polar regions appear to be important. Therefore the inter-model spread of the upper-level temperature difference responses largely reflects the spread of the surface warming in the tropical region, and, with the exception of $\mathrm{SH}$ summer, the inter-model spread of the lower-level temperature difference responses reflects the spread of the polar surface warming. 
Table 1: Inter-model correlation values between the responses of the equator-to-pole temperature differences and the responses of the tropical $(30 \mathrm{~S}-30 \mathrm{~N})$ and polar (north of $60 \mathrm{~N}$ for the $\mathrm{NH}$ differences and south of $60 \mathrm{~S}$ for the $\mathrm{SH}$ differences) surface temperatures. Bold font indicates significance at the $95 \%$ confidence level.

\begin{tabular}{|l|cc|cc|}
\hline & \multicolumn{2}{|c|}{ Winter } & \multicolumn{2}{c|}{ Summer } \\
\hline & Tropical Ts & Polar Ts & Tropical Ts & Polar Ts \\
\hline$\Delta T 850_{\mathrm{NH}}$ & -0.20 & $\mathbf{- 0 . 8 4}$ & -0.15 & $\mathbf{- 0 . 7 7}$ \\
$\Delta T 850_{\mathrm{SH}}$ & 0.17 & $\mathbf{- 0 . 8 0}$ & $\mathbf{0 . 5 3}$ & $\mathbf{- 0 . 5 5}$ \\
$\Delta T 250_{\mathrm{NH}}$ & $\mathbf{0 . 8 6}$ & $\mathbf{0 . 4 7}$ & $\mathbf{0 . 5 7}$ & -0.10 \\
$\Delta T 250_{\mathrm{SH}}$ & $\mathbf{0 . 9 1}$ & 0.12 & $\mathbf{0 . 9 0}$ & 0.30 \\
\hline
\end{tabular}

Consistent with the $\mathrm{NH} / \mathrm{SH}$ difference in the low-level temperature difference correlations, there is no significant inter-model correlation between the upper- and lower-level temperature difference responses in the $\mathrm{NH}$, whereas the upper- and lower-level temperature difference responses in the $\mathrm{SH}$ are correlated with values of 0.45 and 0.50 for DJF and JJA respectively.

\subsection{Storm track regression maps}

To assess the relationship between the responses of the equator-to-pole temperature differences and the responses of the storm tracks, Figure 4 shows the linear regression of the storm track responses on the equator-to-pole temperature difference responses ( $\beta$ from Equation 2 ) for each of the temperature differences.

In both hemispheres there are large regions of positive regression slope. In these regions the storm track increases with the equator-to-pole temperature difference response. This sign of relationship is consistent with the storm track responses being driven by the responses of the baroclinicity, consistent with the study of Hwang et al. (2011). The only regions 
(a) winter $\Delta \mathrm{T} 850$ regression slope

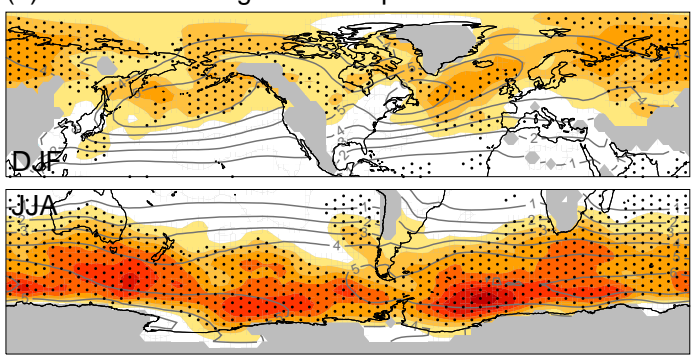

(c) summer $\Delta \mathrm{T} 850$ regression slope

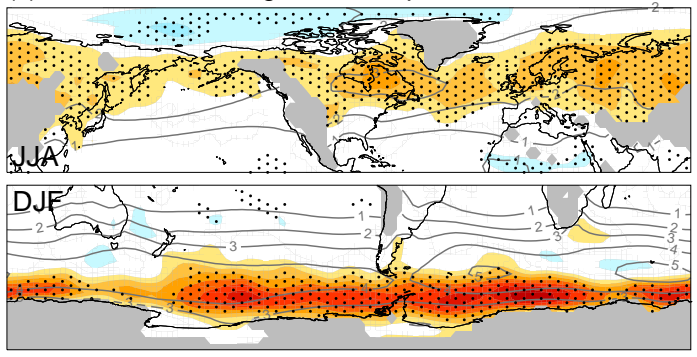

(b) winter $\Delta \mathrm{T} 250$ regression slope

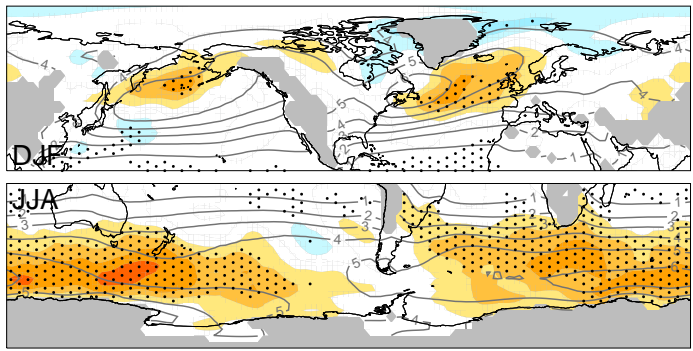

(d) summer $\Delta \mathrm{T} 250$ regression slope
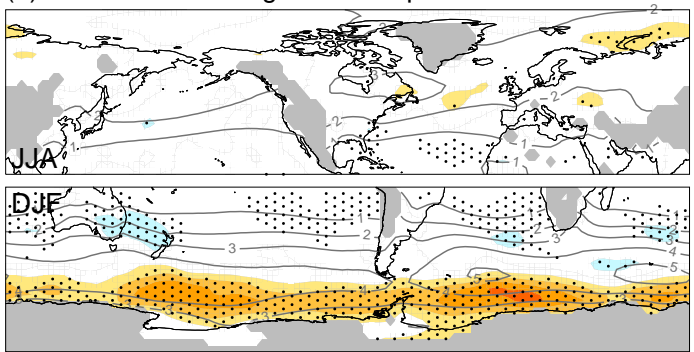

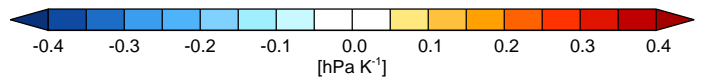

Figure 4: The inter-model regression between the storm track responses and the responses of (a and $\mathbf{c})$ the lower-level temperature differences and ( $\mathbf{b}$ and $\mathbf{d})$ the upper-level temperature differences. Panels $\mathbf{a}$ and $\mathbf{b}$ show winter for each hemisphere and panels $\mathbf{c}$ and $\mathbf{d}$ show summer for each hemisphere. In each sub-plot the regression is performed using the relevant temperature variable for that hemisphere. Stippling indicates a significant correlation at the $95 \%$ confidence level. 
(a) winter $\Delta \mathrm{T} 850 \mathrm{FVE}$

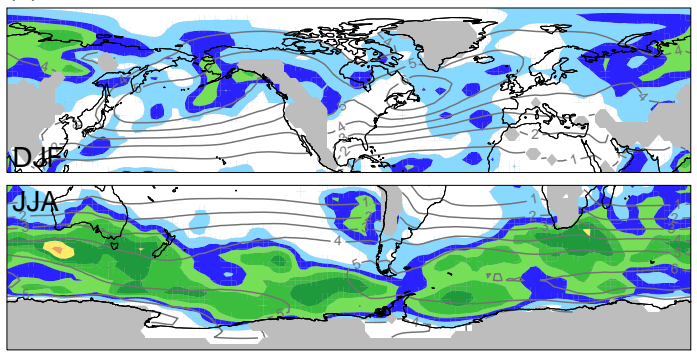

(c) summer $\Delta \mathrm{T} 850 \mathrm{FVE}$
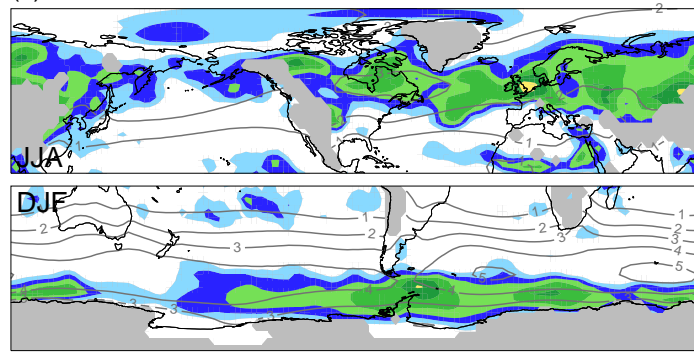

(b) winter $\Delta \mathrm{T} 250 \mathrm{FVE}$

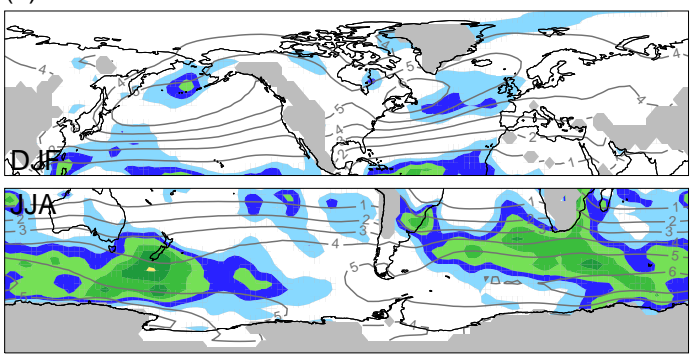

(d) summer $\Delta \mathrm{T} 250 \mathrm{FVE}$
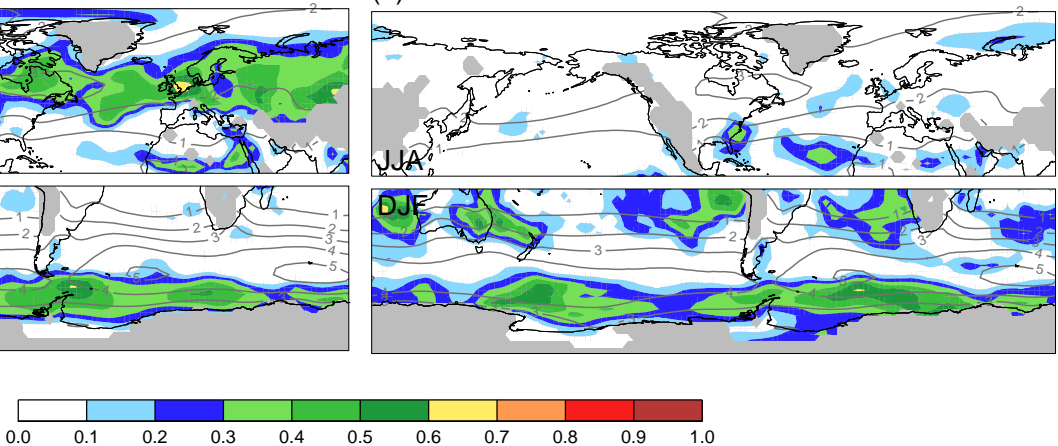

Figure 5: The fraction of inter-model storm track variance explained by the temperature difference regressions of Figure 4. 
with significant negative regression slopes are the Arctic Ocean during summer in the $\Delta T 850$ regression (Figure 4c) and the $\mathrm{SH}$ subtropics during summer in the $\Delta T 250$ regression (Figure 4d). Each hemisphere is now discussed in detail.

\subsubsection{Southern Hemisphere}

In both seasons in the $\mathrm{SH}$ there is a large degree of similarity between the spatial patterns of the regressions for the upper- and lower-level temperature differences. In addition, both regression patterns resemble the spatial structure of both the multi-model mean storm track response and the inter-model standard deviation of Figure 2. In general, the $\Delta T 850_{\mathrm{SH}}$ regression values are than the $\Delta T 250_{\mathrm{SH}}$ regression values; however, the multi-model mean response of $\Delta T 250_{\mathrm{SH}}$ is larger than the multi-model mean response of $\Delta T 850_{\mathrm{SH}}$, by factors of about 3 for DJF and 10 for JJA (see Figure 3). This suggests a dominant role for the upper-level temperature difference in setting the multi-model mean storm track response.

The wintertime regressions (Figures $4 \mathbf{a}$ and $4 \mathbf{b}$ ) show a general strengthening of the storm track across the SH storm track region associated with increasing temperature differences whereas the summertime regressions (Figures $4 \mathbf{c}$ and $4 \mathbf{d}$ ) also have a strengthening but it is confined to a narrow latitudinal band on the southern edge of the storm track, resembling the poleward shift of the mean response. The fraction of inter-model variance explained (FVE; see Figure 5) is over $30 \%$ in much of the $\mathrm{SH}$ storm track region and locally exceeds $50 \%$ in several locations.

The spatial similarity between the upper- and lower-level regression maps is perhaps to be expected given the correlation between the SH temperature differences noted above. However, there are some notable differences between the two maps. For instance, in winter (Figures $4 \mathbf{a}$ and $4 \mathbf{b})$ there is no association between the storm track responses and the $\Delta T 250_{\text {SH }}$ responses in and around the Drake Passage region of the Southern Ocean whereas there is a strong 
association with the $\Delta T 850_{\mathrm{SH}}$ responses. In contrast, in summer the subtropical weakening associated with an increase in $\Delta T 250_{\mathrm{SH}}($ Figure $4 \mathbf{d})$ is not present in the $\Delta T 850_{\mathrm{SH}}$ regression (Figure 4c). This region of negative regression is consistent with static stability dominating the storm track response in the subtropics. There is a high correlation between $\Delta T 250_{\mathrm{SH}}$ and the surface temperature in the tropics (Table 1). Since the dry lapse rate is expected to increase with the surface temperature in the tropics the dry static stability will also be correlated with $\Delta T 250_{\mathrm{SH}}$ (Frierson 2006).

\subsubsection{Northern Hemisphere}

In the NH there is less similarity than in the $\mathrm{SH}$ between the upper- and lower-level regression maps, in either season. In NH summer there is a significant correlation between the storm track responses and the $\Delta T 850_{\mathrm{NH}}$ responses over much of the hemisphere (Figure $4 \mathbf{c}$ ). The spatial pattern of the regression map is similar to the multi-model mean storm track response of Figure 2c, with the opposite sign. Recall from Figure 3a that the multi-model mean JJA response of $\Delta T 850_{\mathrm{NH}}$ is negative and is therefore of the correct sign to explain the multimodel mean storm track response which is negative in the mid latitudes and positive over the Arctic. The FVE by $\Delta T 850_{\mathrm{NH}}$ in the summer is over $40 \%$ in the North Atlantic but less than $30 \%$ in much of the North Pacific. In contrast, there is very little association between the summer NH storm track responses and the $\Delta T 250_{\mathrm{NH}}$ responses in either basin, with small regression values, insignificant correlations and low FVE values.

In $\mathrm{NH}$ winter (Figures $4 \mathbf{a}$ and $4 \mathbf{b}$ ), there is a positive association between the storm track responses and the $\Delta T 850_{\mathrm{NH}}$ responses across most of the northern hemisphere. In contrast, the region of significant association between the storm track responses and the $\Delta T 250_{\mathrm{NH}}$ responses is confined to the ocean basins. The multi-model mean DJF $\Delta T 850_{\mathrm{NH}}$ response is negative (Figure 3) so the impact of $\Delta T 850_{\mathrm{NH}}$ on the multi-model mean storm track response 
is negative, consistent with the weakening of the low-level baroclinicity. The influence on the multi-model mean storm track response from $\Delta T 250_{\mathrm{NH}}$, however, is positive over the ocean basins. The FVE by each temperature difference is low in the $\mathrm{NH}$ winter (Figure 5a) in Atlantic and Pacific storm track regions.

Unlike the results for the $\mathrm{SH}$ and the $\mathrm{NH}$ summer, neither of the two $\mathrm{NH}$ winter regression maps (Figures $4 \mathbf{a}$ and $4 \mathbf{b}$ ) appear to individually capture both the general reduction of the storm tracks in the NH extratropics and the increase over the ocean basins of the multimodel mean storm track response (Figure 2a). However, the two regression maps combined do capture the spatial structure of the multi-model mean response. Figure 6 shows the linear sum of the mean storm track responses predicted by the $\Delta T 850_{\mathrm{NH}}$ and $\Delta T 250_{\mathrm{NH}}$ regression models (that is, the sum of each $\beta$ multiplied by the multi-model mean temperature difference responses) as a simple test of this. A full multiple linear regression has also been performed using the two temperature differences together, however the result is very similar to Figure 6 due to the small correlation between the responses of the two temperature differences noted above. In Figure 6 , the decrease in $\Delta T 850_{\mathrm{NH}}$ is associated with the general decrease in storm activity across the hemisphere in the mean response and the increase in $\Delta T 250_{\mathrm{NH}}$ is associated with the localised increases over the ocean basins. This more complex behaviour, in which the responses are different for the upper- and lower- level temperature differences, is unique to the NH winter and may go some way towards explaining the particularly large inter-model spread in the North Atlantic region.

To test the robustness of both the $\mathrm{NH}$ and $\mathrm{SH}$ regressions to the choice of scenario, the RCP4.5 versions of Figures 2-5 are shown in the Supplementary Material. The text there describes them in detail; here it is just noted that there is a considerable level of agreement between the spatial patterns and magnitudes of the regression maps in RCP4.5 and RCP 8.5 in both seasons in the $\mathrm{SH}$ and in the $\mathrm{NH}$ in summer. However, in $\mathrm{NH}$ winter there is less 


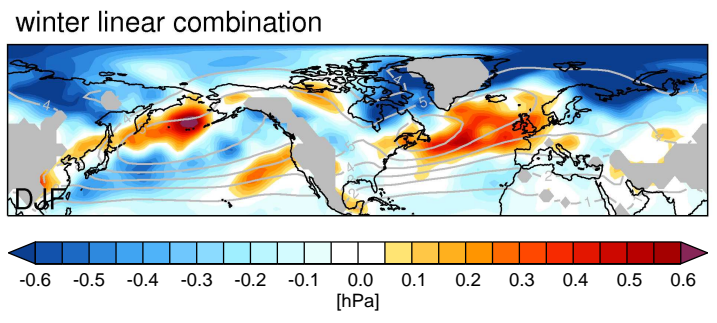

Figure 6: The sum of the mean storm track response predictions for NH winter by the $\Delta T 850$ and $\Delta T 250$ regressions.

agreement: in $\mathrm{RCP} 4.5$ the $\Delta T 850_{\mathrm{NH}}$ responses explain a larger fraction of the variance in the northern North Atlantic than in Figure 5a. The reason for this difference is discussed further in Section 4.

Also shown in the Supplementary Material are regressions of the storm track responses against the global mean surface temperature responses for RCP8.5. Those show that whilst there are some regions with significant correlations present between the storm track responses and the global temperature responses, these are in general weaker and the regressions explain a smaller fraction of the variance than the temperature difference regressions presented here, thus supporting the choice of considering equator-to-pole temperature differences as the regression variable. As discussed in the Supplementary Material, the global mean surface temperature responses are correlated with the $\Delta T 250$ responses, with the exception of $\mathrm{NH}$ JJA, and some aspects of the regression maps reflect this relationship.

\section{A closer look at Northern Hemisphere winter}

In this section the wintertime Northern Hemisphere storm track responses are studied in more detail. Since the zonal-mean temperature difference responses considered above do not account for much of the inter-model spread in the $\mathrm{NH}$ winter, we instead consider longitudinallyconfined measures of the equator-to-pole temperature differences covering each of the two main 
storm track regions of the NH. The aim is to find out whether using more localised equatorto-pole temperature differences can explain a larger fraction of the inter-model variance of the storm track responses.

\subsection{Atlantic and Pacific temperature differences}

The longitudinally-confined equator-to-pole temperature differences used here are defined similarly to the zonal-mean temperature differences used above, except confined to the sectors $10 \mathrm{~W}-60 \mathrm{~W}$ (Atlantic) and $150 \mathrm{E}-220 \mathrm{E}$ (Pacific), and will be denoted as $\Delta T 850_{\mathrm{ATL}}$, $\Delta T 250_{\mathrm{ATL}}, \Delta T 850_{\mathrm{PAC}}$ and $\Delta T 250_{\mathrm{PAC}}$. These sectors are indicated in Figure $7 \mathbf{a}$. Here, as before, the differences are taken between the latitude bands of $30 \mathrm{~S}-30 \mathrm{~N}$ and north of $60 \mathrm{~N}$, and the number indicates the pressure level in $\mathrm{hPa}$.

Figure $7 \mathbf{b}$ shows the range of model responses of these four temperature differences for DJF. The multi-model means and inter-model standard deviations of the responses are similar to the DJF zonal-mean versions of Figure 3 in both basins, with the $\Delta T 250$ responses positive and the $\Delta T 850$ responses negative. The $\Delta T 850$ response is smaller in the Atlantic than in the Pacific, and is positive in three of the models.

\subsection{Atlantic and Pacific storm track regression maps}

Figure 8 shows the storm track regressions and FVE for the responses of the two Atlantic temperature differences $\left(\Delta T 850_{\mathrm{ATL}}\right.$ and $\left.\Delta T 250_{\mathrm{ATL}}\right)$. Both of these regression maps are qualitatively similar to the regression maps from the zonal-mean analysis of Figures $4 \mathbf{a}$ and $4 \mathbf{b}$, with the $\Delta T 850_{\mathrm{ATL}}$ regression positive throughout much of the hemisphere and the $\Delta T 250_{\mathrm{ATL}}$ regression also positive but localised to the ocean basins. However, the regression values in the North Atlantic storm track region are larger for the Atlantic temperature differences than for the zonal-mean temperature differences. The Atlantic sector temperature differences also have larger regions of significant correlation and larger FVE values, exceeding $50 \%$ in a large part 
(a)

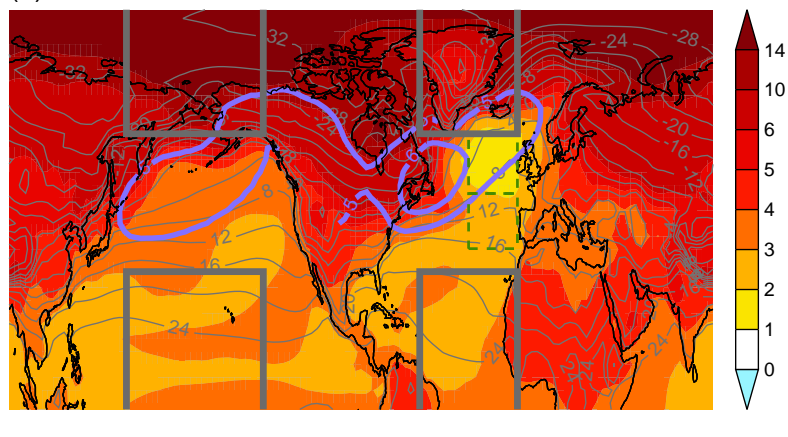

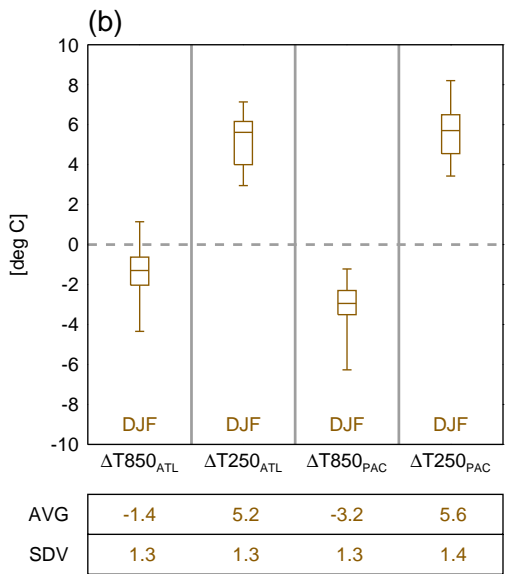

Figure 7: Panel a: Multi-model and DJF mean surface temperature (gray contours; units: $\operatorname{deg} \mathrm{C}$ ) and its RCP8.5 response (shading); the solid-line boxes illustrate Atlantic and Pacific regions used to define the temperature differences defined in Section 4.1, thick contours show the $5 \mathrm{hPa}$ and $6 \mathrm{hPa}$ regions of the multi-model mean HIST storm track (see Figure 2) for reference and the small dashed-line boxes in the North Atlantic show the two regions discussed in Section 4.2. Panel b: Box-and-whisker symbols illustrating the median, interquartile range and the full range of the individual model responses of the DJF Atlantic and Pacific temperature differences; the lower section displays the multi-model mean (AVG) and inter-model standard deviation (SDV) of each index. 
(a) winter $\Delta \mathrm{T} 850_{\mathrm{ATL}}$ regression slope

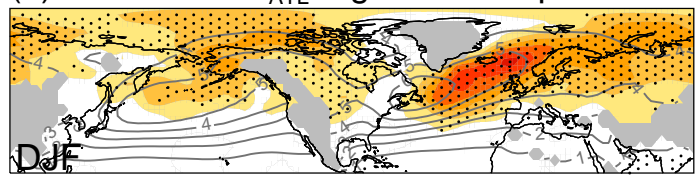

(b) winter $\Delta \mathrm{T} 250_{\mathrm{ATL}}$ regression slope

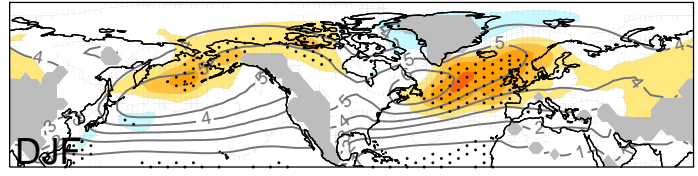

(d) winter $\Delta T 250_{A T L} F V E$ (c) winter $\Delta \mathrm{T} 850_{\mathrm{ATL}} \mathrm{FVE}$

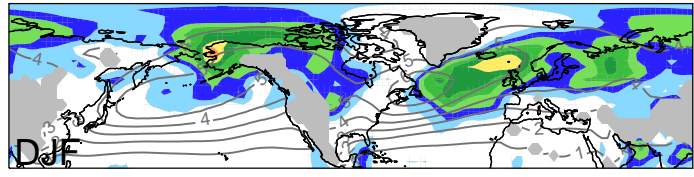

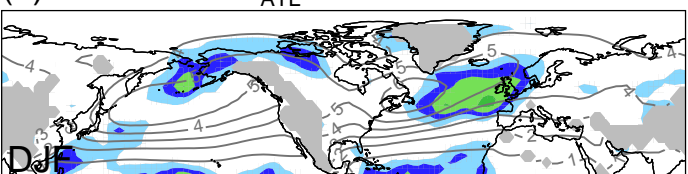

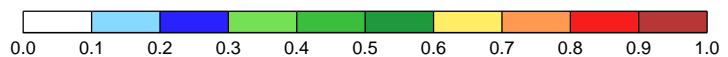

Figure 8: Regression analysis based on the North Atlantic temperature differences. Panels a and $\mathbf{b}$ : The inter-model regression between the storm track responses and the responses of the lower- and upper-level temperature differences respectively; stippling indicates a significant correlation at the $95 \%$ confidence level. Panels $\mathbf{c}$ and $\mathbf{d}$ : The FVE by the regression of the lower- and upper-level temperature differences respectively.

(a) winter $\triangle \mathrm{T} 850_{\mathrm{PAC}}$ regression slope

(c) winter $\Delta \mathrm{T}_{250_{\mathrm{PAC}}}$ regression slope

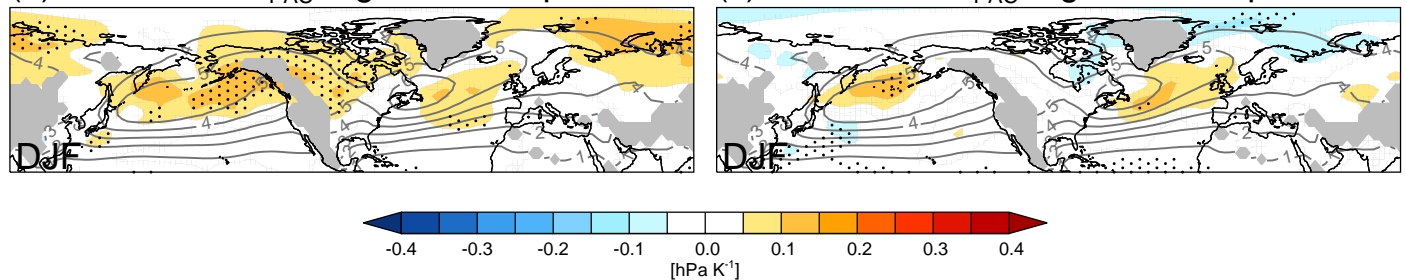

(b) winter $\triangle \mathrm{T} 850_{\mathrm{PAC}} \mathrm{FVE}$

(d) winter $\Delta \mathrm{T} 250_{\mathrm{PAC}} \mathrm{FVE}$
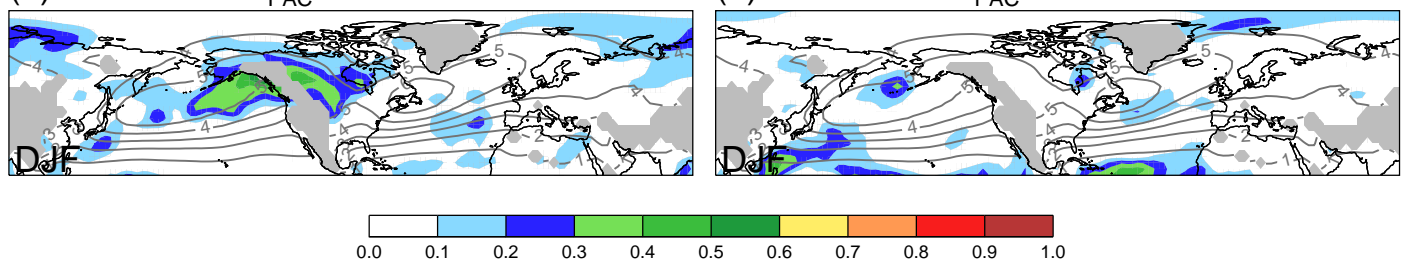

Figure 9: Regression analysis based on the North Pacific temperature differences. The panels are ordered as in Figure 8. 
of the North Atlantic for $\Delta T 850_{\mathrm{ATL}}$, than the zonal-mean temperature differences. Therefore the Atlantic temperature difference responses have a stronger association with the North Atlantic wintertime storm track responses than the zonal-mean temperature differences.

Despite the high FVE in the North Atlantic using this method, care must be taken when inferring a physical mechanism for the change. For example, Woollings et al. (2012) argue that the North Atlantic wintertime storm track responses are influenced by changes in the ocean circulation, via changes in the sea surface temperature (SST) and ice edge position, both of which may potentially impact the North Atlantic storm track. As a simple test of the role of the local surface temperature responses compared to the role of the large-scale equatorto-pole measures considered here, a further regression analysis has been performed between the storm track responses and the responses of the local East Atlantic meridional surface temperature gradient. This is defined as the difference in temperature between the small solid-lined boxes in the East Atlantic in Figure 7: 10W-35W, 30N-47N and 10W-35W, 47N$60 \mathrm{~N}$. This definition is chosen to capture the changes in SST gradient suggested by Woollings et al. (2012) to be important for the North Atlantic storm track responses, and in particular the region of mediated warming in the central North Atlantic associated with a reduction of the Atlantic Meridional Overturning Circulation (Drijfhout et al. 2012). The responses of this local surface temperature difference are strongly correlated with the $\Delta T 850_{\mathrm{NH}}$ responses in winter $(r=0.64)$ and as a result the regression slope map (not shown) is very similar to the $\Delta T 850$ regression slope map of Figure 8a (see also Figure $1 \mathbf{f}$ of Woollings et al. (2012)). This emphasises how it is not clear from this analysis whether the storm track responses are driven directly by the large-scale equator-to-pole temperature differences or instead by the local surface temperature gradient responses.

Figure 9 shows the linear regressions and FVE by the responses of the two Pacific temperature differences $\left(\Delta T 850_{\mathrm{PAC}}\right.$ and $\left.\Delta T 250_{\mathrm{PAC}}\right)$ and the responses of the storm tracks. There is 
a striking difference between these plots and those of the zonal mean analysis in Figures 4 and 5 in that over much of the hemisphere the association between the Pacific sector temperature differences and the storm track is no larger than with the zonal mean temperature differences of Figure 4. Therefore the responses of the local equator-to-pole temperature differences do not appear to have a strong association with the storm track in the wintertime North Pacific. This suggests that other processes, for instance changes to the zonal structure of Tropical Pacific SSTs (Vecchi et al. 2006), which will not project onto the equator-to-pole temperature differences used here, may be influencing the responses of the Pacific storm track.

Again, the RCP4.5 version of Figures 8 and 9 are shown in the Supplementary Material. In contrast to the zonal-mean temperature difference regressions discussed in Section 3.3, the $\Delta T 850_{\mathrm{ATL}}$ regressions are very similar between $\mathrm{RCP} 4.5$ and $\mathrm{RCP} 8.5$. Therefore the difference between the RCP4.5 and RCP8.5 zonal-mean temperature difference regressions noted above is due to how well correlated the $\Delta T 850_{\mathrm{ATL}}$ and $\Delta T 850_{\mathrm{NH}}$ responses are. Consistent with this, the inter-model correlations between these two variables are larger for RCP4.5 (0.81) than for RCP8.5 (0.67).

In summary, the Atlantic basin equator-to-pole temperature difference responses have a stronger association with North Atlantic storm track responses than the zonal-mean equatorto-pole temperature difference responses do, and the regression maps are similar between RCP4.5 and RCP8.5. In contrast, the association between the Pacific basin equator-to-pole temperature difference responses and the North Pacific storm track responses does not appear to be any stronger than that of the zonal mean equator-to-pole temperature differences used in Section 3. 


\section{Summary and Discussion}

The aim of this study has been to determine the relationship between the responses of the storm tracks and the responses of the equator-to-pole temperature differences in the CMIP5 climate projections. A simple linear regression analysis has been performed on the storm track responses and the responses of both zonal-mean and basin-wide measures of the upperand lower-tropospheric equator-to-pole temperature difference. Whilst allowing insight into the sources of the spread between the models, this method also highlights the possible drivers of the mean storm track responses.

In each of the main storm track regions there are regions where the storm track responses are significantly correlated $(p=0.05)$ with both the upper- and lower-tropospheric temperature difference responses in both the summer and winter seasons. The only exception to this are the upper-tropospheric temperature difference responses in $\mathrm{NH}$ summer which show no significant correlation with the NH storm track responses. In the $\mathrm{SH}$ the upper- and lowertropospheric temperature difference responses are correlated and there are strong similarities between the two regression maps. In the $\mathrm{NH}$ the two temperature difference responses are not significantly correlated and the regression maps are qualitively different. Regarding the mean responses predicted by the regression analysis:

- In the SH in summer and winter both the upper- and lower-tropospheric temperature difference regression maps are qualitatively similar to the multi-model mean storm track responses.

- In the $\mathrm{NH}$ in summer the lower-tropospheric temperature difference regression map is qualitatively similar to the multi-model mean storm track response, whereas the regression values for the upper-tropospheric temperature difference are small.

- In the NH in winter the upper- and lower-tropospheric temperature difference regressions 
do not individually capture the full spatial structure of the multi-model mean storm track response; however, the linear combination of the two regressions does resemble the multi-model mean storm track response.

- Over large parts of the main storm track regions the sign of the regression is such that an increase in equator-to-pole temperature difference is associated with an increase in storm activity.

The first three points suggest that in addition to explaining some of the differences between the models, the changes in the equator-to-pole temperature differences play a role in setting the multi-model mean climate change response of the storm tracks, and the final point is consistent with the storm tracks responding to the baroclinicity changes. Regarding the inter-model spread:

- In the $\mathrm{SH}$ there are large regions in both the summer and winter seasons where the responses of both the upper- and lower-level temperature difference responses explain over $30 \%$ of the inter-model variance of the storm track responses, and in some localised regions this is over $50 \%$.

- In the NH the response of the upper-level temperature difference explains only a small fraction of the inter-model variance in both seasons; the response of the lower-level temperature difference explains over $40 \%$ of the inter-model variance in the North Atlantic in summer, but only small amounts elsewhere.

This suggests that the spread due to model uncertainty in the climate change projections of the extratropical storm tracks may be reduced by constraining the relative temperature responses of the tropical and polar regions.

The small fraction of variance explained in $\mathrm{NH}$ winter by the zonal-mean temperature differences has been investigated further using equator-to-pole temperature differences re- 
stricted to the Atlantic and Pacific ocean basins in turn. The resulting regression maps are qualitatively similar to the zonal-mean temperature difference regression maps, however:

- Over much of the North Atlantic the responses of the lower- and upper-level Atlantic temperature differences explain more of the inter-model variance of the storm track responses than the zonal-mean equator-to-pole temperature differences do, with values exceeding $50 \%$ and $30 \%$ respectively.

- Over the North Pacific there is little increase in the fraction of inter-model storm track variance explained by the responses of the Pacific temperature differences.

Therefore the North Atlantic wintertime storm track appears to be more sensitive to the local equator-to-pole temperature differences, whereas in the North Pacific other factors may dominate the storm track responses.

One limitation of this study is the use of a single measure of storm activity. In particular, as noted by Burkhardt \& James (2006) and Chang (2009), Eulerian statistics such as the bandpass filtered MSLP variance used here are potentially susceptible to Doppler effects whereby changes in the mean propagation speed of storm systems cause power to 'Doppler shift' in to or out of the time filter window. Testing this by assessing the storm track responses using multiple measures of storm activity will be the subject of a future study.

Another limitation of the method used here is that the causality of the correlations cannot be determined. For instance, whilst the responses of the low-level Atlantic equator-to-pole temperature difference explains over $50 \%$ of the inter-model variance in the North Atlantic, it is not clear whether the storm tracks respond directly to the equator-to-pole temperature difference or instead respond to more local baroclinicity changes, such as those caused by changes in sea ice, SSTs or the land-sea temperature contrast, which may themselves be correlated with the equator-to-pole temperature differences. In order to test this relationship, atmosphere-only GCM experiments will be run to isolate the impact on the storm track of 
changes in SSTs and sea ice verses changes in the large-scale baroclinicity. The results will be published in a future paper.

\section{Acknowledgements}

BJH was supported by the Natural Environment Research Councils project Testing and Evaluating Model Predictions of European Storms (TEMPEST) during the course of this work. The authors wish to thank Giuseppe Zappa for help in obtaining the CMIP5 data, and the two anonymous reviewers for their useful comments on the manuscript. In addition, we acknowledge the World Climate Research Programme's Working Group on Coupled Modelling, which is responsible for CMIP, and we thank the climate modeling groups for producing and making available their model output. For CMIP the U.S. Department of Energy's Program for Climate Model Diagnosis and Intercomparison provides coordinating support and led development of software infrastructure in partnership with the Global Organization for Earth System Science Portals.

\section{References}

Bengtsson, L. \& Hodges, K. I. 2006 Storm Tracks and Climate Change. J. Clim. 19, pp. $3518-3543$.

Burkhardt, U. \& James, I. N. 2006 The effect of Doppler correction on measures of storm track intensity. Clim. Dyn. 27, pp. 515-530.

Butler, A. H., Thompson, D. W. J. \& Heikes, R. 2010 The steady-state atmospheric circulation response to climate change-like thermal forcings in a simple general circulation model. $J$. Clim. 23, pp. 3474-3496.

Catto, J. L., Shaffrey, L. C. \& Hodges, K. I. 2011 Northern Hemisphere extratropical cyclones 
in a warming climate in the HiGEM high resolution climate model. J. Clim. 24, pp. 53365352.

Chang, E. K. M. 2009 Are band-pass variance statistics useful measures of storm track activity? Re-examining storm track variability associated with the NAO using multiple storm track measures. Clim. Dyn. 33, pp. 277-296.

Chang, E. K. M., Guo, Y. \& Xia, X. 2013 CMIP5 multimodel ensemble projection of storm track change under global warming. J. Geosphy. Res. 117, p. D23,118.

Dailey, P., Huddleston, M., Brown, S. \& Fasking, D. 2009 The financial risks of climate change. Association of British Insurers Technical report, AIR Worldwide Corp and the UK Met Office.

Drijfhout, S., van Oldenburgh, G. V. \& Cimatoribus, A. 2012 Is a Decline of AMOC Causing the Warming Hole above the North Atlantic in Observed and Modeled Warming Patterns? J. Clim. 25, pp. 8373-8379.

Duchon, C. E. 1979 Lanczos filtering in one and two dimensions. J. of Applied Met. 18, pp. $1016-1022$.

Frierson, D. M. W. 2006 Robust increases in midlatitude static stability in simulations of global warming. Geophys. Res. Lett. 33, p. L24,816.

Geng, Q. \& Sugi, M. 2003 Possible change of extratropical cyclone activity due to enhanced greenhouse gases and sulfate aerosols-study with a high-resolution AGCM. J. Clim. 16, pp. 2262-2274.

Harvey, B. J., Shaffrey, L. C., Woollings, T. J., Zappa, G. \& Hodges, K. I. 2012 How large are projected 21st century storm track changes? Geophys. Res. Lett. 39, p. L052,873. 
Hernández-Deckers, D. \& von Storch, J. S. 2010 Energetics responses to increases in greenhouse gas concentration. J. Clim. 23, pp. 3874-3887.

Hoskins, B. J. \& Hodges, K. I. 2002 New perspectives on the Northern Hemisphere winter storm tracks. J. Atmos. Sci. 59, pp. 1041-1061.

Hwang, Y.-T., Frierson, D. M. W. \& Kay, J. E. 2011 Coupling between Arctic feedbacks and changes in poleward energy transport. Geophys. Res. Lett. 38, p. L17,704.

Lim, E. P. \& Simmonds, I. 2009 Effect of tropospheric temperature change on the zonal mean circulation and SH winter extratropical cyclones. Clim. Dyn. 33, pp. 19-32.

Lunkeit, F., Fraedrich, K. \& Bauer, S. E. 1998 Storm tracks in a warmer climate: sensitivity studies with a simplified global circulation model. Clim. Dyn. 14, pp. 813-826.

Moss, R. H., Edmonds, J. A., Hibbard, K. A., Manning, M. R., Rose, S. K., van Vuuren, D. P., Carter, T. R., Emori, S., Kainuma, M., Kram, T. et al. 2010 The next generation of scenarios for climate change research and assessment. Nature 463, pp. 747-756.

Pinto, J. G., Fröhlich, E. L., Leckebusch, G. C. \& Ulbrich, U. 2007 Changing European storm loss potentials under modified climate conditions according to ensemble simulations of the ECHAM5/MPI-OM1 GCM. Nat. Hazards and Earth Sys. Sci. 7, pp. 165-175.

Rind, D. 2008 The consequences of not knowing low-and high-latitude climate sensitivity. Bull. Am. Meteor. Soc. 89, pp. 855-864.

Sansom, P. G., Ferro, C. A. T., Zappa, G., Shaffery, L. \& Stephonson, D. B. 2013 Simple uncertainty frameworks for selecting weighting schemes and interpreting multi-model ensemble climate change experiments. J. Clim., p. in press.

Schneider, T., O'Gorman, P. A. \& Levine, X. J. 2010 Water vapor and the dynamics of climate changes. Rev.Geophys. 48, p. RG3001. 
Schwierz, C., Köllner-Heck, P., Zenklusen Mutter, E., Bresch, D. N., Vidale, P. L., Wild, M. \& Schär, C. 2010 Modelling European winter wind storm losses in current and future climate. Climatic change 101, pp. 485-514.

Solomon, S., Qin, D., Manning, M., Chen, Z., Marquis, M., Averyt, K., M.Tignor \& Miller, H., editors 2007 IPCC, 2007: Climate Change 2007: The Physical Science Basis. Contribution of Working Group I to the Fourth Assessment Report of the Intergovernmental Panel on Climate Change. Cambridge University Press, Cambridge, United Kingdom and New York, NY, USA.

Taylor, K. E., Stouffer, R. J. \& Meehl, G. A. 2012 An Overview of CMIP5 and the Experiment Design. Bull. Amer. Meteor. Soc. 94, pp. 485-498.

Ulbrich, U., Leckebusch, G. C. \& Pinto, J. G. 2009 Extra-tropical cyclones in the present and future climate: a review. Theo. and Appl. Clim. 96, pp. 117-131.

Ulbrich, U., Pinto, J., Kupfer, H., Leckebusch, G., Spangehl, T. \& Reyers, M. 2008 Changing northern hemisphere storm tracks in an ensemble of IPCC climate change simulations. $J$. Clim. 21, pp. 1669-1679.

Vecchi, G. A., Soden, B. J., Wittenberg, A. T., Held, I. M., Leetmaa, A. \& Harrison, M. J. 2006 Weakening of tropical Pacific atmospheric circulation due to anthropogenic forcing. Nature 441, pp. $73-76$.

Woollings, T., Gregory, J. M., Pinto, J. G., Reyers, M. \& Brayshaw, D. J. 2012 Response of the North Atlantic storm track to climate change shaped by ocean-atmosphere coupling. Nat. Geosci. 5, pp. 313-317.

Yin, J. H. 2005 A consistent poleward shift of the storm tracks in simulations of 21st century climate. Geophys. Res. Lett. 32, p. L18,701. 
Zappa, G., Shaffrey, L. C., Hodges, K. I., Sansom, P. G. \& Stephenson, D. B. 2013 A multimodel assessment of future projections of North Atlantic and European extratropical cyclones in the CMIP5 climate models. J. Clim. . 